\title{
11. IS THE COMPREHENSIVE ASSESSMENT REALLY COMPREHENSIVE?
}

\author{
Emilio Barucci ${ }^{1}$, Roberto Baviera ${ }^{1}$ and Carlo Milani ${ }^{2}$
}

\begin{abstract}
The Comprehensive Assessment is the first action taken by the European Central Bank as supervisor of the banking sector in the euro area according to the Single Supervisory Mechanism. The key question relies on whether the exercise was truly comprehensive or not. The database, made available by the central bank and the European Banking Authority, allows to verify for the possibility of double standards with respect to banks' business models (traditional credit activity versus financial assets) and to their country of origin. Answers are surprising on both aspects.
\end{abstract}

\subsection{INTRODUCTION}

A few days before the start of the Single Supervisory Mechanism, on the 26th of October 2014, the results of the Comprehensive Assessment (CA) were released: CA can be considered the true kick off of the European Banking Union. CA was performed by the European Central Bank (ECB), in collaboration with the European Banking Authority (EBA) and the national competent authorities, in order to check financial health of the banks that ECB would have supervised within few days.

Two were the main tasks of the CA: i) it tried to define a level playing field in the euro-area banking sector, harmonizing the different national approaches to supervision, and ii) it sought for an adequate level of capitalization for European banks assessing their main risks. These two tasks were addressed through two 'exercises' that complement each other: the Asset Quality Review (AQR) which was focused more on the first task and a Stress Test (ST) analysis, tuned more on the second task. In the ST there were a baseline scenario and an adverse scenario, where the baseline scenario was derived from the (country specific) European Commission's three year forecasts while the adverse scenario was a downward perturbation of the baseline.

Nicola Bruti Liberati Quantitative Finance LAB, Department of Mathematics, Politecnico di Milano, 32 p.zza L. da Vinci, I-20133 Milano; emilio.barucci@polimi.it (Corresponding Author); roberto.baviera@polimi.it.

2 BEM Research, 86 viale Primo Maggio, I-00047 Marino (Roma), c.milani@bemresearch.it. 
While ST can be considered nowadays a 'standard' methodology for the banking sector in both in USA and Europe, the AQR was a detailed analysis of a selection of banks portfolios with the explicit mandate of harmonization on both traditional credit activity (e.g. the definition of non-performing exposure, impairment triggers, provisioning approaches for going concern non-performing exposures and point-in-time collective provisioning) and financial assets (mainly on the valuation methodologies of the most complex financial assets in a bank's balance sheet - i.e. level 3 assets - and on CVA - credit value adjustment - calculation).

The AQR led to EUR 48 billion (bn) of adjustments to bank assets, while the capital adjustment related to the adverse ST scenario was EUR $263 \mathrm{bn}$, a median $4 \%$ reduction in the Common Equity Tier 1 (CET1) ratio (ECB, 2014).

Due to the relevance and novelty of the exercise in the euro area, several are the relevant questions that could be addressed. In this short contribution we just aim to identify whether the exercise was truly comprehensive and we verify for the possibility of double standards with respect to banks' business models and to their country of origin. For broader questions as the capability of the CA to capture bank risk we refer to Acharya and Steffen (2014) and Barucci et al. (2016).

In order to achieve this objective, we investigate the determinants of the capital shortfall of a bank, considering two different measures: i) shortfall with respect to the AQR and ii) shortfall after the CA. The latter is obtained as the maximum of the three shortfalls (AQR and two ST scenarios) and it amounts to EUR 24.6 bn for 25 banks (ECB, 2014). As explanatory variables, we include country and balance sheet variables.

Our main findings are as follows: a) the assessment was biased against banks specializing in traditional activity; b) the leverage ratio performs better than the risk-weighted capital ratio, i.e. the CET1 ratio, in capturing the shortfall of the $\mathrm{CA} ; \mathrm{c})$ the shortfall seems to depend on the country where the banking group is incorporated.

Even a purely descriptive analysis shows that the AQR exercise concentrated predominantly on traditional credit activity rather than on the financial assets detained by banks: only EUR 1.4 bn of the AQR adjustments were due to asset evaluation adjustments, EUR 3.1 bn came from the revision of CVA values while EUR 43 bn came from credit adjustments (ECB, 2014). Our analysis confirms this observation: the AQR shortfall and the CA shortfall are positively affected by the role of credit activity but they are not influenced by the presence of the financial assets, even those extremely difficult to evaluate (level 3 assets).

Our analysis sheds some light on the banking capital debate. As expected, the AQR shortfall is negatively affected by the CET1 ratio and by the leverage ratio. 
However, we show that the CA shortfall is affected by the leverage ratio, whereas the CET1 ratio does not play any explanatory role. This view reinforces the scepticism concerning the reliability of risk-weighted capital ratios following the financial crisis (for European stress tests in 2011 and in 2014, see e.g. Acharya et al., 2014; Acharya and Steffen, 2014; Haldane, 2012; Le Leslé and Avramova, 2012).

Furthermore, our results show some evidence that the CA shortfall depends on the country in which the bank group is incorporated: banks located in peripheral countries are penalized in comparison to those of core countries.

The remaining part of the paper is organized as follows. In Section 2 we describe the empirical model and we present our main results, both on the AQR shortfall and on the shortfall of the CA as a whole. In Section 3 we conclude and underline some policy implications.

\subsection{EMPIRICAL MODEL AND MAIN RESULTS}

We analyse bank-level data from the ECB and the EBA, with respect to shortfalls after the AQR and the ST. The CA involved 130 banks for the AQR with total assets of EUR 22 trillion (tr) and risk-weighted assets (RWAs) of EUR $8.5 \mathrm{tr}$, which account for $81.6 \%$ of the banking system under the umbrella of the Single Supervisory Mechanism. The AQR focused on bank assets as at the end of 2013, while the ST performed a scenario analysis on a three-year window up to 2016. Our sample is made up of 129 banks operating in the euro area ${ }^{3}$.

The gross domestic product (GDP) figures are 2013 values from the World Bank database.

Our research strategy is to estimate the shortfall of a bank associated with the AQR and with the CA (maximum of the shortfalls of the AQR, of the ST under the baseline scenario and of the ST under the adverse scenario). We refer respectively to the two shortfalls as $S F_{-} A Q R$ and $S F_{-} C A$. The capital shortfalls are obtained as the absolute value of the differences (floored at zero) between the CET1 ratio obtained after the AQR or the ST and the associated thresholds $18 \%$ for the AQR, 8\% in 2016 post ST under the baseline scenario and 5.5\% in 2016 post ST under the adverse scenario).

We omit data from Deutsche Bank Malta because of the abnormal CET1 ratio (281\%). 
We consider the following reference model:

$$
\begin{aligned}
\text { SF }_{-} Y_{i}= & k+\beta_{1} \cdot \text { cap }_{i}+\beta_{2} \cdot \text { lasset }_{i}+\beta_{3} \cdot \text { lasset }_{i}^{2}+\beta_{4} \cdot \text { npe }_{i}+\beta_{5} \cdot \text { cr }_{i}+ \\
& \beta_{6} \cdot \text { sys }_{i}+\beta_{7} \cdot \text { marketcap }_{j}+\beta_{8} \cdot \text { level }_{i}+\gamma \cdot X+\varepsilon_{i}
\end{aligned}
$$

where $S F_{-} Y_{i}$ denotes either the AQR or CA shortfalls of bank $i$, expressed in EUR bn. In the model we include two types of exogenous variables: bank-specific variables (lower case $i$ ) and a country specific variable (lower case $j$ ) that refers to the country in which the bank holding company is located.

We control for the size of the bank using the logarithm of total assets (lasset) and we allow for nonlinearities by also including the square of this variable (lasset $\left.{ }^{2}\right)$. The size of the balance sheet size could provide a control variable for the level of the shortfall for several reasons: on the one hand, a large bank is more likely to be supervised by the market and therefore the need for intervention from the supervisory authority could be less intense; on the other hand, a large bank is riskier from a systemic risk perspective, thus potentially making supervision softer or tougher. To investigate further how the bank's relevance affects the CA exercise, we also consider the ratio of the assets of the bank over the nominal GDP of the country in which the bank is incorporated (sys). This ratio should explicitly capture the systemic relevance associated with a bank in terms of the relationship between size and systemic risk (see e.g. Laeven et al., 2014).

There is a still open debate on the appropriate capital ratio (risk-adjusted versus non-risk-adjusted) that should be considered in order to capture the riskiness of a bank's balance sheet. This debate leads us to introduce as capital ratio (cap) either the CET1 ratio (cet1) or the leverage ratio $(l r)^{4}$. If a capital ratio is a reliable indicator of the bank's solidity, it should have a negative effect on the size of the shortfall for the AQR and for the CA as a whole. Note that the shortfall is defined with respect to CET1 thresholds and thus (in an obvious way) a lower shortfall should be associated with a higher CET1 ratio as a starting point (both for the $\mathrm{AQR}$ and for the CA as a whole).

We investigate how the composition of the balance sheet affects the shortfall. To capture how credit quality affects the shortfall of the AQR and of the CA, we consider the ratio of non-performing exposures over total exposures (npe) and the coverage ratio for non-performing exposures $(c r)$, i.e. the ratio between credit loss provision funds and non-performing exposures. As far as the asset component is concerned, we consider the proportion of level 3 assets to total assets (level3).

The leverage ratio is computed as CET1 capital over total assets and measured according to the Capital Requirements Regulation under the Capital Requirements Directive. 
For the country-specific variables, we consider stock exchange market capitalization over nominal GDP (marketcap). Our goal is to control for a market discipline effect that may substitute supervisory scrutiny. Our hypothesis is that an economy with a well-developed financial market should be characterized by lower AQR and ST shortfalls because the market has already imposed on banks adequate capitalization/risk management tools.

We complete our analysis by inserting two further explicative variables. The dummy variable Drestruct takes a value equal to 1 in the case of a bank undergoing a restructuring process before 31 December 2013 and 0 otherwise: a restructuring plan for a bank is usually accompanied by tougher activity by the supervisory authority, deleveraging/cleaning of the books and public or private capital injections. We also include the dummy variable Dirb (which takes a value equal to 1 in the case of a bank with more than $50 \%$ of its RWAs computed according to the internal rating model) to check whether banks use the discretion of Basel II/III agreements to reduce RWAs (see e.g. Mariathasan and Merrouche, 2014).

We estimate (1) using a Tobit estimator, which overcomes the problem of inconsistent results derived from using the ordinary least squares estimator when the dependent variable is truncated (see Wooldridge, 2002).

Let us stress that according to the Basel II/III framework, if regulatory and supervisory activities work properly, then the CET1 ratio should provide exhaustive information about the soundness of the bank while other indicators should be redundant.

The reference model is estimated and the results are reported in Table 1, p. 100.

As expected, we find that a high CET1 ratio negatively affects the shortfall of the AQR (model I).

However, considering SF_CA, the relationship is not confirmed. It seems that the CET1 ratio was considered a reliable capital indicator by national authorities and the ECB during the AQR, but that it was not able to capture adequately the risks of a bank and therefore the shortfall of the CA is not negatively affected by the CET1 ratio (models $\mathrm{V}$ and VI). On the other hand, the leverage ratio turns out to be always highly significant (models III, IV, VII and VIII): leveraged banks (low ratio) are characterized by higher capital shortfalls. In contrast to the general paradigm of the Basel II/III regulation, grounded on risk-adjusted capital ratios, this evidence signals that the CA's capital shortfalls are mainly driven by the leverage ratio.

As far as bank size is concerned, we observe an inverted $U$ shape: the $S F \_A Q R$ and SF_CA of medium-sized banks are higher than the shortfalls for small and 
Table 1. Regression results - reference model for capital shortfall.

The table reports the estimation results based on the Tobit estimator.

\begin{tabular}{|c|c|c|c|c|c|c|c|c|}
\hline & Model & & & & & & & \\
\hline & I & II & III & IV & $\mathrm{V}$ & VI & VII & VIII \\
\hline Dependent variable & SF_AQR & SF_AQR & SF_AQR & SF_AQR & SF_CA & SF_CA & SF_CA & SF_CA \\
\hline \multirow[t]{2}{*}{ cet1 } & $-0.098^{* * *}$ & $-0.099 * * *$ & - & - & -0.071 & -0.079 & - & - \\
\hline & {$[0.027]$} & {$[0.020]$} & & & {$[0.046]$} & [0.049] & & \\
\hline \multirow[t]{2}{*}{$\operatorname{lr}$} & - & - & $-0.188^{* * *}$ & $-0.194 * * *$ & - & - & $-0.617 * * *$ & $-0.652 * * *$ \\
\hline & & & {$[0.059]$} & {$[0.057]$} & & & {$[0.148]$} & {$[0.143]$} \\
\hline \multirow[t]{2}{*}{ lasset } & $0.615^{* * *}$ & $0.786^{* *}$ & 0.873 & $1.143^{* *}$ & $1.750^{* *}$ & $1.841^{* *}$ & 1.574 & 1.663 \\
\hline & {$[0.188]$} & {$[0.343]$} & {$[0.605]$} & {$[0.560]$} & {$[0.805]$} & {$[0.872]$} & [0.987] & [1.089] \\
\hline \multirow[t]{2}{*}{ lasset $^{2}$} & $-0.060 * *$ & -0.082 & -0.130 & $-0.174^{* *}$ & $-0.195^{* *}$ & $-0.222^{* *}$ & -0.200 & -0.229 \\
\hline & {$[0.025]$} & {$[0.052]$} & [0.094] & {$[0.083]$} & {$[0.098]$} & {$[0.110]$} & {$[0.123]$} & {$[0.142]$} \\
\hline \multirow[t]{2}{*}{ npe } & $0.021 * *$ & $0.031^{* * *}$ & $0.054^{* * *}$ & $0.065^{* * *}$ & $0.096^{* * *}$ & $0.100 * * *$ & $0.153^{* * *}$ & $0.160 * * *$ \\
\hline & [0.009] & {$[0.011]$} & {$[0.012]$} & {$[0.018]$} & {$[0.035]$} & {$[0.036]$} & {$[0.033]$} & {$[0.031]$} \\
\hline \multirow[t]{2}{*}{$\mathrm{cr}$} & $-0.010^{*}$ & $-0.019 * * *$ & $-0.012 *$ & $-0.022 * *$ & $-0.020^{* *}$ & $-0.020^{*}$ & 0.006 & 0.006 \\
\hline & {$[0.005]$} & {$[0.006]$} & {$[0.007]$} & [0.009] & {$[0.010]$} & {$[0.011]$} & [0.009] & [0.011] \\
\hline \multirow[t]{2}{*}{ sys } & $-0.005^{*}$ & $-0.012 * * *$ & $-0.008^{* * * *}$ & $-0.015^{* * *}$ & -0.013 & $-0.019^{*}$ & $-0.016^{* * *}$ & $-0.023^{* * *}$ \\
\hline & {$[0.003]$} & {$[0.004]$} & {$[0.002]$} & {$[0.004]$} & {$[0.009]$} & {$[0.010]$} & [0.007] & {$[0.008]$} \\
\hline \multirow[t]{2}{*}{ marketcap } & $-0.010^{* * *}$ & $-0.018 * * *$ & $-0.016^{* * *}$ & $-0.024^{* * *}$ & $-0.026^{* * *}$ & $-0.034^{* * *}$ & $-0.038^{* * *}$ & $-0.050^{* * * *}$ \\
\hline & [0.004] & {$[0.005]$} & {$[0.007]$} & {$[0.007]$} & {$[0.012]$} & {$[0.014]$} & {$[0.010]$} & [0.013] \\
\hline \multirow[t]{2}{*}{ level3 } & -0.087 & $-0.149^{*}$ & -0.044 & -0.057 & 0.057 & 0.041 & 0.019 & -0.030 \\
\hline & {$[0.071]$} & {$[0.079]$} & [0.059] & {$[0.067]$} & {$[0.129]$} & [0.126] & {$[0.112]$} & {$[0.110]$} \\
\hline \multirow[t]{2}{*}{ Drestruct } & - & $0.696^{* * *}$ & - & $0.737 * * *$ & - & $1.041^{*}$ & - & $1.207^{* *}$ \\
\hline & & {$[0.234]$} & & {$[0.273]$} & & [0.592] & & {$[0.518]$} \\
\hline \multirow[t]{2}{*}{ Dirb } & - & $-0.196^{*}$ & - & -0.216 & - & 0.255 & - & 0.085 \\
\hline & & [0.099] & & {$[0.152]$} & & {$[0.496]$} & & [0.396] \\
\hline \multirow[t]{2}{*}{ constant } & -0.082 & 0.135 & -0.214 & -0.047 & -2.768 & -2.515 & -0.533 & -0.026 \\
\hline & [0.359] & {$[0.546]$} & {$[1.013]$} & [1.077] & {$[1.775]$} & [1.977] & [1.904] & [2.048] \\
\hline \multirow[t]{2}{*}{ sigma } & $0.279 * * *$ & $0.206^{* * *}$ & $0.404^{* * * *}$ & $0.357^{* * *}$ & $1.338 * * *$ & $1.287^{* * *}$ & $1.020 * * *$ & $0.933 * * *$ \\
\hline & {$[0.068]$} & [0.029] & {$[0.071]$} & {$[0.053]$} & {$[0.255]$} & {$[0.236]$} & [0.159] & [0.117] \\
\hline F statistic (p-value) & 0.000 & 0.000 & 0.000 & 0.000 & 0.004 & 0.005 & 0.000 & 0.000 \\
\hline Uncensored obs & 16 & 16 & 16 & 16 & 25 & 25 & 25 & 25 \\
\hline Obs & 129 & 129 & 129 & 129 & 129 & 129 & 129 & 129 \\
\hline
\end{tabular}

Notes: Cluster-robust standard errors appear in parentheses. We use Stata11 for all calculations. $*, * *, * *$ indicate statistical significance of the parameters at the $10 \%, 5 \%$ and $1 \%$ significance levels respectively. 
large banks. The fact that large banks were not penalized by the CA is confirmed by the negative and significant coefficient associated with the variable capturing the systemic nature of the bank (sys). We can interpret this evidence as showing that the supervisors are captive to large banks. However, it may be the case that large banks are able to evaluate their assets more carefully or possibly were subject to greater supervision in the past due to the 'too big to fail' problem.

The role of financial markets can be easily understood: a well-developed financial market (represented by the variable marketcap) negatively affects both $S F \_A Q R$ and $S F_{-} C A$. This result illustrates the role of market supervision (Basel II's third pillar), which complements the activity of the supervisory authority (Basel II's second pillar).

Looking at the composition of the balance sheet, credit activity and financial assets play a different role. On the one hand, we observe that the shortfall is inflated by the ratio of non-performing loans, representing an indicator of the quality of credit: lower quality (higher ratio) induces a more significant shortfall; a phenomenon partially balanced by a high coverage ratio that negatively affects the shortfall (weakly in the case of the CA as a whole). On the other hand, surprisingly, the proportion of level 3 assets over total assets does not affect the shortfall of either the AQR or the CA: this outcome signals that the CA fails to capture higher risks related to illiquid and complex financial activities.

Taking into account the additional explanatory variables with respect to the reference model, we find first that the role of restructuring plans (Drestruct) is significant and robust as the specification varies: a bank under restructuring is characterized by a higher shortfall of the AQR and of the CA as a whole. Second, the coefficient associated with the dummy variable measuring whether a bank relies on the internal rating approach (Dirb) is rarely statistical significant: we can deduce that according to the CA, the adoption of the internal-based model is not associated with risk weight manipulation.

Looking at the overall fitness of the models, we find that the standard error of the regression (sigma) is the lowest when the CET1 ratio is included with the $S F_{-}$ $A Q R$ as the dependent variable (model II), while the best fit for the $S F_{-} C A$ is obtained by including the leverage ratio (model VIII).

We also develop our analysis comparing banks by country of origin. The CA exercise was followed by a dispute about the possibility that the ECB adopted double standards with respect to banks depending on their country of origin; to address this point, we provide some regressions considering among the exogenous variables a dummy variable (Dcore), which assumes a value equal to 1 in the case that a bank is incorporated in one of the core countries (Austria, Belgium, Germany, Finland, France, Luxembourg and the Netherlands) and 0 otherwise (peripheral countries). In Table 2 we provide some regressions for $S F_{-} A Q R$. 
Table 2. Regression results - Core vs non-core country effects on capital shortfall in the AQR.

The table reports the estimation results based on the Tobit estimator.

Dependent variable: SF_AQR

\begin{tabular}{|c|c|c|c|c|c|c|}
\hline & \multicolumn{6}{|c|}{ Model } \\
\hline & I & II & III & IV & V & VI \\
\hline \multirow[t]{2}{*}{ cet1 } & $-0.092 * * *$ & - & - & $-0.105^{* * *}$ & $-0.103 * * *$ & $-0.100 * * *$ \\
\hline & {$[0.018]$} & & & {$[0.017]$} & [0.014] & [0.016] \\
\hline \multirow[t]{2}{*}{ lasset } & $0.773 *$ & $0.759 * *$ & $1.166^{* *}$ & $0.754^{* *}$ & $0.908^{* * *}$ & $0.613 * *$ \\
\hline & [0.328] & {$[0.323]$} & {$[0.509]$} & [0.290] & [0.332] & {$[0.284]$} \\
\hline \multirow[t]{2}{*}{ lasset $^{2}$} & -0.080 & -0.078 & $-0.181^{* *}$ & $-0.078^{*}$ & $-0.103^{* *}$ & -0.051 \\
\hline & {$[0.050]$} & {$[0.050]$} & {$[0.077]$} & [0.044] & {$[0.052]$} & {$[0.043]$} \\
\hline \multirow[t]{2}{*}{ sys } & $-0.011 * * *$ & $-0.012 * * *$ & $-0.014 * * *$ & $-0.011 * * *$ & $-0.012 * * *$ & - \\
\hline & {$[0.004]$} & {$[0.003]$} & {$[0.005]$} & [0.003] & [0.003] & \\
\hline \multirow[t]{2}{*}{ marketcap } & $-0.019 * * *$ & $-0.027^{* * *}$ & $-0.025^{* *}$ & $-0.024 * * *$ & $-0.027 * * *$ & $-0.022 * * *$ \\
\hline & [0.004] & {$[0.003]$} & {$[0.010]$} & [0.003] & [0.004] & [0.003] \\
\hline \multirow[t]{2}{*}{ Drestruct } & $0.804 * * *$ & $1.039 * * *$ & $0.806^{* *}$ & $0.909 * * *$ & $1.017^{* * *}$ & $0.929 * * *$ \\
\hline & [0.223] & {$[0.155]$} & {$[0.406]$} & [0.157] & [0.185] & [0.141] \\
\hline \multirow[t]{2}{*}{ Dirb } & -0.201 & $-0.254 * * *$ & -0.093 & $-0.196^{*}$ & -0.163 & $-0.328 * * *$ \\
\hline & [0.126] & {$[0.081]$} & [0.193] & [0.103] & {$[0.105]$} & [0.092] \\
\hline \multirow[t]{2}{*}{ 1-Dcore } & $0.410^{* * *}$ & $-2.397^{* * * *}$ & -0.092 & $-0.447^{*}$ & $-0.830^{*}$ & -0.197 \\
\hline & [0.147] & [0.809] & {$[0.960]$} & {$[0.248]$} & [0.433] & {$[0.165]$} \\
\hline \multirow[t]{2}{*}{ npe } & $0.025 *$ & $0.018 * *$ & $0.054^{* * *}$ & - & $0.019^{* *}$ & $0.021 * * *$ \\
\hline & [0.010] & {$[0.008]$} & [0.016] & & {$[0.008]$} & {$[0.008]$} \\
\hline \multirow[t]{2}{*}{$\mathrm{cr}$} & $-0.028 * * *$ & -0.006 & -0.027 & -0.008 & - & $-0.020^{* * * *}$ \\
\hline & [0.009] & {$[0.008]$} & [0.019] & {$[0.006]$} & & [0.006] \\
\hline \multirow[t]{2}{*}{ level3 } & $-0.232 * *$ & $-0.170 * *$ & -0.114 & $-0.165 *$ & $-0.154 * *$ & $-0.221^{* * *}$ \\
\hline & [0.090] & {$[0.075]$} & {$[0.188]$} & {$[0.071]$} & [0.076] & [0.079] \\
\hline \multirow[t]{2}{*}{ cet $1 \times$ Dcore } & - & $-0.398 * * *$ & - & - & - & - \\
\hline & & [0.089] & & & & \\
\hline \multirow[t]{2}{*}{ cet $1 \times(1$-Dcore $)$} & - & $-0.103 * * *$ & - & - & - & - \\
\hline & & {$[0.014]$} & & & & \\
\hline \multirow[t]{2}{*}{ Ir $\times$ Dcore } & - & - & $-0.419 * *$ & - & - & - \\
\hline & & & {$[0.203]$} & & & \\
\hline \multirow[t]{2}{*}{$\operatorname{lr} \times(1-D c o r e)$} & - & - & $-0.157 * * *$ & - & - & - \\
\hline & & & {$[0.050]$} & & & \\
\hline \multirow[t]{2}{*}{ npexDcore } & - & - & - & $-27.057 * * *$ & - & - \\
\hline & & & & [7.951] & & \\
\hline \multirow[t]{2}{*}{ npex(1-Dcore) } & - & - & - & $1.849 * *$ & - & - \\
\hline & & & & {$[0.736]$} & & \\
\hline cr $\times$ Dcore & - & - & - & - & $-4.618 * * *$ & - \\
\hline
\end{tabular}


Table 2. Regression results - Core vs non-core country effects on capital shortfall in the AQR.

The table reports the estimation results based on the Tobit estimator.

Dependent variable: SF_AQR

\begin{tabular}{|c|c|c|c|c|c|c|}
\hline & \multicolumn{6}{|c|}{ Model } \\
\hline & I & II & III & IV & $\mathrm{V}$ & VI \\
\hline & & & & & {$[0.819]$} & \\
\hline \multirow[t]{2}{*}{$\operatorname{cr} \times(1-D c o r e)$} & - & - & - & - & -0.359 & - \\
\hline & & & & & {$[0.898]$} & \\
\hline \multirow[t]{2}{*}{ sys $\times$ Dcore } & - & - & - & - & - & $-0.135^{* * *}$ \\
\hline & & & & & & {$[0.029]$} \\
\hline \multirow[t]{2}{*}{ sys $\times(1-$ Dcore $)$} & - & - & - & - & - & $-0.011^{* * * *}$ \\
\hline & & & & & & {$[0.003]$} \\
\hline \multirow[t]{2}{*}{ constant } & 0.205 & $2.548^{* * * *}$ & 0.311 & 0.639 & $0.672 *$ & $0.904^{*}$ \\
\hline & {$[0.468]$} & {$[0.565]$} & {$[1.021]$} & {$[0.404]$} & {$[0.401]$} & {$[0.469]$} \\
\hline \multirow[t]{2}{*}{ Sigma } & $0.183^{* * *}$ & $0.160^{* * * *}$ & $0.337^{* * *}$ & $0.165^{* * *}$ & $0.164^{* * *}$ & $0.162^{* * *}$ \\
\hline & {$[0.025]$} & {$[0.026]$} & {$[0.048]$} & {$[0.024]$} & {$[0.025]$} & {$[0.027]$} \\
\hline$\beta_{\text {Dcore }}=\beta_{\text {(1-Dcore) }}(\mathrm{p}$-value $)$ & - & 0.001 & 0.172 & 0.000 & 0.002 & 0.000 \\
\hline$\left.\frac{\delta S F_{\text {Daqre }}}{\delta Z_{\text {Dcore }}}\right|_{Z}$ & - & $-5.518^{* * * *}$ & $-1.773 * *$ & $-58.026^{* * *}$ & $-189.6^{* * * *}$ & $-3.523 * *$ \\
\hline$\left.\frac{\delta S F_{-a q r}}{\delta Z_{(1-\text { Dcore })}}\right|_{Z}$ & - & $-3.542^{* * *}$ & -1.054 & $18.775^{* *}$ & -16.382 & $-0.552^{* * *}$ \\
\hline F statistic (p-value) & 0.000 & 0.000 & 0.000 & 0.000 & 0.000 & 0.000 \\
\hline Uncensored obs & 16 & 16 & 16 & 16 & 16 & 16 \\
\hline Obs & 129 & 129 & 129 & 129 & 129 & 129 \\
\hline
\end{tabular}

Notes: Cluster-robust standard errors appear in parentheses. We use Stata11 for all calculations. $*, *, * *$ indicate statistical significance of the parameters at the $10 \%, 5 \%$ and $1 \%$ significance levels respectively. Derivatives are evaluated at the median value of the $Z$ control variable interacted with Dcore and (1-Dcore).

We consider the variable 1-Dcore (Model I) and then we interact it with five different exogenous variables: i) CET1 ratio; ii) leverage ratio; iii) non-performing exposure; iv) coverage ratio; v) systemic risk indicator (models II to VI). To check whether the effect of core countries is statistically different from that of non-core ones, we report the Wald test for the equality of the coefficients. We also report the derivative of the five exogenous variables evaluated at the median value for the two different groups of countries.

First we observe that the effect of the 1-Dcore variable, without interactions, on the shortfall of the AQR is positive and significant (model I). Then we notice that the coefficients of some exogenous variables (cet1, npe, $\mathrm{cr}$ and sys) interacted 
with Dcore and 1-Dcore are statistically different. In absolute values, the coefficients associated with banks incorporated in core countries are higher than the coefficients associated with banks incorporated in non-core countries. A high CET1 ratio (model II) for a bank of a core country negatively affects the shortfall more than in the case of a bank of a peripheral country. With respect to nonperforming exposures, we find that the effect is positive and significant in the case of peripheral countries, while it is negative and significant for core countries (model IV). Confirming this evaluation, the effect of the coverage ratio in core countries is negative and significant, while in peripheral countries it is not significant (model V). Finally, we notice that the systemic risk indicator associated with a large bank implies a milder impact for credit institutions operating in core countries than for those located in peripheral ones (model VI).

These results can be interpreted in two different ways: either as a signal of 'favour' (severity) of country regulators in peripheral (core) countries before the CA exercise, or as evidence that the AQR was benevolent (tough) towards banks incorporated in core (non-core) countries.

\subsection{CONCLUSIONS AND POLICY IMPLICATIONS}

The results of the CA raised a number of questions related to the fact that it was not neutral. In particular, two issues were widely discussed: i) the CA was biased towards traditional credit activity; ii) banks located in peripheral countries were penalized.

The analysis of the shortfall of the CA provided in this paper highlights that some factors affect the shortfall besides the CET1 ratio starting point: i) banks located in non-core countries were penalized by the AQR; ii) medium-sized banks are either more risky or were penalized by the $\mathrm{CA}$; iii) poor credit quality and credit specialization are the main balance sheet features driving the shortfall, while the proportion of assets that it is difficult to evaluate plays no role. Moreover, we find that the CET1 ratio is significant in explaining the shortfall of the AQR, but not in explaining the shortfall of the CA.

However, the leverage ratio is always significant: a less leveraged bank would experience a lower shortfall.

These results provide three interesting policy insights. First of all, the analysis shows that the leverage ratio constraint introduced by the Basel III regulation is a better indicator of financial soundness than the classic risk-weighted capital ratio. As the actual Basel III calibration of the leverage ratio is soft (see Basel Committee on Banking Supervision, 2015), the suggestion is to set a sharper constraint on the leverage ratio. The second implication is that the European 
Banking Union marks an important step in harmonizing the banking sector at the European level considering that the national regulatory/supervisory standards were quite heterogeneous before the CA. However, our analysis shows that the ECB's supervision activity needs refinement as it is overly concentrated on traditional activity with a limited focus on the evaluation of financial assets. As the financial crisis has shown that complex assets evaluated according to a model may be a source of instability, a tougher approach by the ECB towards these assets seems necessary. Considering all these aspects, some doubts emerge about the ability of the CA to be really comprehensive. From this perspective, the Supervisory Review and Evaluation Process (SREP), promoted by the EBA and ECB from 1 January 2016, seems to be a useful step as the experience of the Federal Reserve (2015) suggests.

\section{REFERENCES}

ACharya, V., ENGle, R. and PIERrET, D., 2014, “Testing macroprudential stress tests: the risk of regulatory risk weights", Journal of Monetary Economics, 65: 36-53.

ACHARYA, V. and STEFFEN, S., 2014, Benchmarking the European Central Bank's asset quality review and stress test: a tale of two leverage ratios, VOX, November 2014.

BARUCCI, E., BAVIERA, R. and MILANI, C., 2016, Is the comprehensive assessment able to capture banks' risks?, to appear in Finance Research Letters.

BASEl COMMITTEE ON BANKING SuPERVISION, 2015, Basel III, monitoring report, mimeo.

EUROPEAN CENTRAL BANK, 2014, Aggregate report on the comprehensive assessment, available on http://goo.gl/qgnqWU.

Federal Reserve, 2015, Comprehensive Capital Analysis and Review 2015: Assessment Framework and Results, Federal Reserve, Washington DC, available on www.federalreserve.gov/newsevents/press/bcreg/ bcreg20150311a1.pdf.

Haldane, A., 2012, The dog and the frisbee, Bank of England, mimeo.

LAEven, L., RATNOVSKi, L. and TONG, H., 2014, Bank size and systemic risk, IMF Staff Discussion Note, 14/04.

LE LESLÉ, V. and AVRAMOVA, S., 2012, Revisiting risk-weighted assets, IMF working paper, $12 / 90$.

Mariathasan, M. and Merrouche, O., 2014, "The manipulation of Basel risk weights", Journal of Financial Intermediation, 23: 300-321.

WOOLDRIDGE, J. M., 2002, Econometric analysis of cross section and panel data, Cambridge, MA: The MIT Press. 